Chapter 8

\title{
GNSS Observations of Crustal Deforamtion: A Case Study in East Asia
}

Shuanggen Jin

Additional information is available at the end of the chapter

http://dx.doi.org/10.5772/51536

\section{Introduction}

The East Asia is located in a complex convergent region with several plates, e.g., Pacific, North American, Eurasian, and Philippine Sea plates. Subduction of the Philippine Sea and Pacific plates and expulsion of Eurasian plate with Indian plate collision [22, 36, 15, 18, 11] make the East Asia as one of the most active seismic and deforming regions (Fig. 1). Current deformation in East Asia is distributed over a broad area extending from the Tibet in the south to the Baikal Rift zone in the north and the Kuril-Japan trench in the east, with some ambiguous blocks, such as South China (Yangtze), Ordos and North China blocks, and possibly the Amurian plate, embedded in the deforming zone. The inter-plate deformation and interaction between the blocks are very complicated an active, such as the $1978 \mathrm{Mw}=7.8$ Tangshan earthquake located between North China and Amurian blocks. Since the 1960s when the theory and models of seafloor spreading and plate tectonics were established, the large Eurasian plate has been considered as an independent rigid plate, such as RM2, P071 and NNR-NUVEL1A [6], and even the present-day global plate motion models of ITRF sequences based on the space geodetic data [10]. In fact, East Asia is very complicated deformation zone with several possible rigid blocks [22]. [36] proposed that East Asia consists of several micro-plates. However, because of low seismicity and there being no clear geographical boundary except for the Kuril-Japan trench and the Baikal rift zone, it is difficult to accurately determine the geometry and boundary of sub-plates in these areas. The borderlines of the micro-plates are not visible, especially in the complicated geological tectonic regions in North China far away from the Qinghai-Tibet plateau, and convergent belts of Eurasia, North America and the Pacific plate. Therefore, it is difficult to confirm the tectonic features and evolution of the deformation belts in East Asia. 
In the northern part of East Asia, [36] first proposed the existence of the Amurian plate based on the clear geographical boundary of the Kuril-Japan trench and the Baikal rift zone, but it becomes diffuse throughout continental East Asia. The proposed Amurian plate (AM) in East Asia is of special interest to constrain the relative motion of the major and minor plate in East Asia and provides a rigorous framework for interpreting seismicity and the kinematics, especially for seismically active Japan. However, the southern boundary of the suggested Amurian plate is poorly understood. Figure 1 shows some recent proposed boundaries. The upper blue solid line is from [4], the middle black dash boundary line is from [34], and the bottom red dash line is from [8].

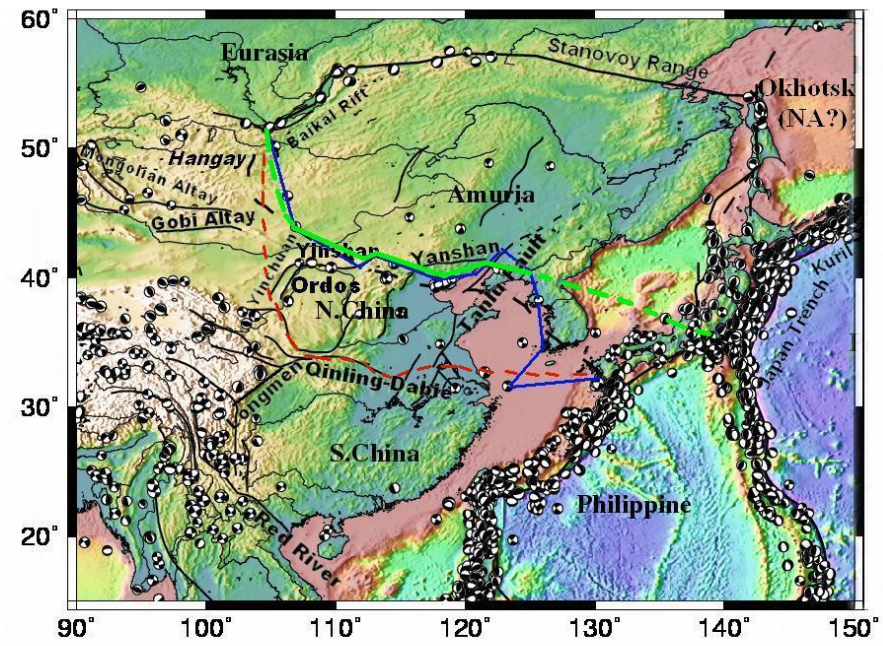

Figure 1. Tectonics setting in East Asia. The un-continuous lines are the main fault lines and the dash lines are the undefined plate boundary. Circles are the earthquakes from Harvard CMT catalogue (1976-2005, Mw >5.0). The upper blue solid line is from [4], the middle black dash boundary line is from [34], the bottom red dash line is from [8], and the upper green solid+dash lines is this study.

Therefore, the existence of the Amurian plate and its boundary geometry remain controversial. Over the last two decades a number of investigations of the micro-plates tectonics in East Asia have been conducted using geologic, seismological and geodetic data $[36,34,8,27$, $5,2]$. However all of these studies have suffered from limited data quality and quantity, resulting in ambiguous conclusions. For instance, [34] estimated the AM motion with earthquake slip vectors and found that the spreading rates of the Baikal Rift are with the order of $<1 \mathrm{~mm} / \mathrm{yr}$. [8] assumed Amuria and North China as an independent Amurian plate, and estimated spreading rates at the Baikal Rift were about $10 \mathrm{~mm} / \mathrm{yr}$. [29] used only four GPS sites in or around the AM plate and concluded that AM can neither be resolved nor exclud- 
ed as a separate plate.[5] postulated that North China (including the possible AM) and South China could be a single rigid block using data from only 9 GPS sites. [2] claimed the existence of the Amurian plate, but still could not determine the location of the southern Amurian plate boundary. These investigations of the tectonics in this region are not conclusive because of the sparse and limited data that were used. Hence, there is much debate surrounding the nature of microplate and its boundaries in East Asia.

With more GPS observations in East Asia, it provides a new ways to clearly monitor the large-scale crustal motion and to distinguish the possible blocks, e.g., the national projects "Crustal Movement Observation Network of China (CMONC) with more than 1000 GPS sites and the Japanese GPS Earth Observation Network (GEONET) with more than 1000 continuous GPS sites. These dense GPS observations will obtain a more accurate estimate of plate geometry and its interior crustal deformation in East Asia. In this Chapter, we present new dense geodetic results for East Asia from about 1000 GPS sites in China, South Korea and Japan for the period 1998-2005, as well as combining recently published velocities for the Bailkal Rift and Mongolia [5]. The possibility of microplate motion independent of the Eurasian plate is tested using GPS derived velocities and its boundary and kinematics are further discussed [13].

In addition, accurate measurements of crustal strain accumulated energy rates will contribute to understand tectonic features and to evaluate the earthquake potential. Now the high precision space geodesy techniques, especially the low-cost and all weather GPS, play a key role in monitoring the crustal strain state and accumulated energy variation. Meanwhile, the significant strain accumulation caused by the tectonic activities (such as earthquakes) will provide an essential constraint on the physical processing of earthquakes. Therefore, monitoring the spatial variation of the strain and comprehensive understanding of strain accumulation pattern are beneficial to reveal the physical process of crustal tectonic activities and to evaluate the earthquake risk [14]. Here, the denser GPS velocity filed is used to estimate the strain rates and strain energy density rates, in an attempt to know largely aseismic areas and to assess the future earthquake risk potential in East Asia.

\section{GPS observations and results}

The Crustal Movement Observation Network of China (CMONC) was constructed since 1998, which contains a nationwide fiducial network of 25 continuous GPS sites observed since August 1998, 56 survey mode sites with yearly occupations and more than 900 regional campaign stations operated in 1999, 2001, and 2004 with continuous observations for at least 4 days during each session. In addition, the Korean GPS Network (KGN) with more than 45 permanent GPS sites was established since 2000 by the Korea Astronomy and Space Science Institute (KASI), the Ministry Of Governmental Administration and Home Affairs (MOGAHA), and the National Geographic Information Institute (NGI). Japan GPS Earth Observation Network (GEONET) was established since 1996 by the Geographical Survey Institute of Japan. These denser GPS observations can investigate and study detailed crustal 
deformation and kinematics in East Asia. Here we collect about 1000 GPS sites (1999.12004.12) in East Asia with 54 core IGS sites that were used for ITRF2000 [1] and 10 permanent IGS sites located in East Asia. These GPS sites are shown in Figure 2. The pentagon stands for the permanent GPS sites (2000-2005), the dot denotes the campaign GPS sites and the triangle is the yearly observed GPS sites (1999-2005).

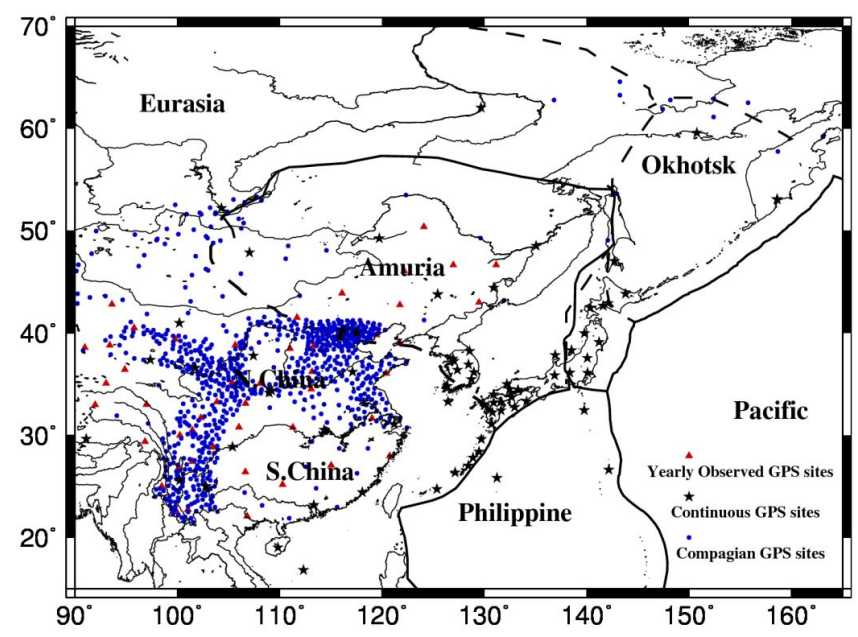

Figure 2. GPS sites distribution in this study. The triangle is the yearly observed GPS site, the pentagon is the continuous GPS site (2000-2005), and the dot is the campaign GPS site (1999-2005). The solid lines are the known plate boundaries.

All available GPS data were processed in single-day solutions using the GAMIT software [16] in a three-step approach. At the first step, loose a-priori constraints were set for all parameters and double-differenced GPS phase observations from each day were used to estimate station coordinates and the zenith tropospheric delay (ZTD) at each station every 2 hours. The IGS final orbits, IERS Earth orientation parameters, azimuth- and elevation-dependent antenna phase center models, as recommended by the IGS were used in the data processing. The 54 global IGS stations served as ties to the ITRF2000 frame [1]. At the second step, the regional daily solutions were combined with global solutions produced by the Scripps Orbital and Position Analysis Center (SOPAC, http://sopac.ucsd.edu/) using the GLOBK software [9], and the reference frame was applied to the solution by performing a seven-parameter transformation to align it to ITRF2000 (via the global 54 core stations). At the third step, the site velocities were estimated by least square linear fitting to time variations of the daily coordinates for each station [13]. For example, Figure 3 shows the North, East and Vertical GPS time series at SUWN site (South Korea). The 1000 GPS site velocity field combining with recently published velocities at the Baikal Rift and Mongolia [5] are shown in Figure 4 with respect to the Eurasian plate. 

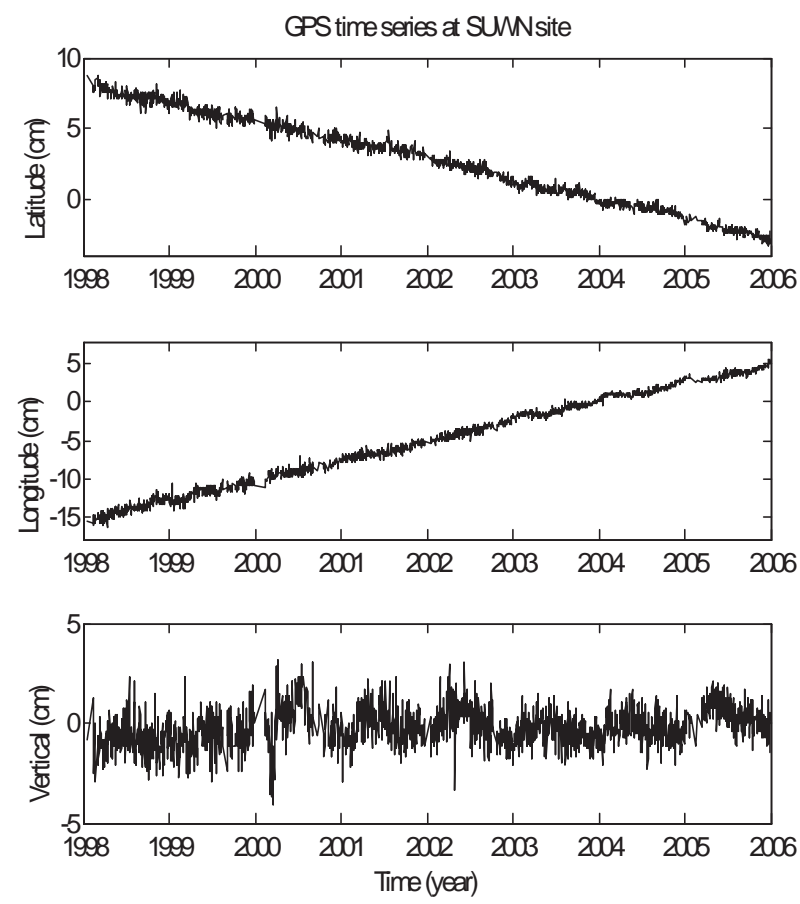

Figure 3. GPS time series at SUWN site (South Korea).

\section{Sub-plates and kinematics}

\subsection{Block modeling method}

The definition of the micro-plate geometries in East Asia is quite unclear, especially their boundaries. Denser space geodetic data can be used to define the plate boundary by testing an independent plate rotation about a best-fit Euler's rotation pole obtained by geodetic velocities. Here we assumed several plates or blocks in NE Asia whose plate boundary geometries were defined principally on the basis of seismicity and faults: EU (Eurasia), AM (Amuria), SK (South Korea), NC (North China), SC (South China), AK(AM+SK), AN (AK $+\mathrm{NC}$ ), EA (East Asia) (see Figure 1). The boundaries are respectively the Yin Shan-Yan Shan Mountain belts for AM-NC, the Qinling-Dabie fault for NC-SC and the Tanlu fault for NCSK blocks. As the blocks have large areas, the plates are just defined as rigid blocks motions without considering the elastic strain [32], i.e. 


$$
v=\Omega \times r
$$

where $v$ is the velocity and $r$ is the position vector. In order to calculate Euler's rotation parameters, we project the fault geometry and stations positions from spherical to planar geometry [20]. Then the rigid block motion are modeled to estimate the Euler ration parameters of each block (see Table 1). Here only continuously and yearly observed GPS stations are used. In addition, the angular velocity of the Eurasian plate was estimated from the velocities of 22 IGS sites located on the Eurasian plate (TROM, MADR, HERS, BRUS, KOSG, 7203, ZIMM, VILL, OBER, ONSA, WETT, POTS, GOPE, GRAS, BOR1, LAMA, KIRU, JOZE, ZWEN, IRKT, KIT3, KSTU), including the core sites in the Eurasian plate employed for the orientation and maintenance of the ITRF2000 [1] (see Table 1).

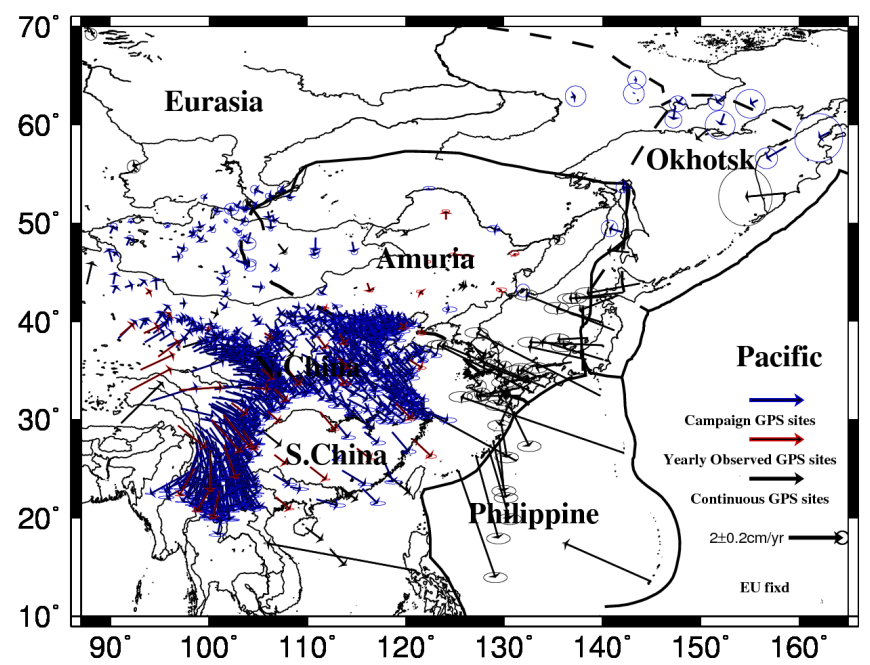

Figure 4. Crustal deformation rates in the Eurasia plate (EU) fixed reference frame with error ellipses in 95\% confidence limits.

\subsection{Testing results}

To test whether the microblocks are independent of the Eurasian plate, we used a $\chi^{2}$ test that compares how well two different models fit a set of data. $\chi^{2}$ is a sum of the squares of weighted residuals defined as:

$$
\chi^{2}=\sum_{i=1}^{N} \frac{\left(v_{o}(i)-v_{m}(i)\right)^{2}}{\sigma_{o}^{2}(i)}
$$


where $v_{o}(i)$ is the observation velocity of site $i, v_{m}(i)$ is the calculated velocity of site $i$ from the plate rotation model, $\sigma_{o}^{2}(i)$ is the variance of observation velocity in site $i$, and $N$ is the total number of observations. Table 2 shows the $\chi^{2}$ for each model. The $\chi^{2}$ for the model of independent AM, SK, SC, NC blocks is smaller than the Eurasian plate and a 2-block model (EU and EA), respectively. To check whether AM, SK, SC and NC are independent blocks, we perform an F-ratio statistical test.

First, we assume the one-block model in which East Asia (EA) is part of the Eurasian plate and the two-block model in which the East Asia (EA) plate rotates independently with respect to the Eurasian plate (EU). The 3-block model assumes that the EA is divided into the AN (Amuria+South Korea+North China) and South China (SC) plates, while the 4-block model contains the EU, SC (S.China), NC (N.China) and AK (Amuria+S.Korea) plates. The 5block model is the EU, SC, NC, AM and SK plates. These blocks were defined principally on the basis of seismicity and faults (see Figure 1). We compare the misfit of each model inversion and test for significance using the F-ratio [30]:

$$
F=\frac{\left[\chi^{2}(1 \text { block })-\chi^{2}(2 \text { block })\right] / 3}{\chi^{2}(2 \text { block }) /(N-3)}
$$

where $\chi^{2}(1$ block $)$ and $\chi^{2}(2$ block $)$ stand for the sum of the squares of weighted residuals in one-block and two-block models, respectively. In Table 2 one can clearly see that for the two-block model (EU and EA) the reduced chi-squared misfit of GPS velocity observations has been greatly reduced from 6.4 (for the one-block model (EU+EA)) to 1.4 (for the twoblock model (EU and EA)) and the F-ratio statistic (Eq.2) is 1086.5, which is well above the $99 \%$ confidence level of 3.8. The reduced chi-squared misfits of other independently rotating blocks for the 3-block, 4-block and 5-block models are also greatly degraded, and the calculated F-statistics between the 2-3 block and 3-4 block models are well above the $99 \%$ confidence level of 3.8 as well as between the 3-4 block and 4-5 block models. These results indicate that the AM, SK, NC and NC are independent of the Eurasian plate motion. Furthermore, it shows that the South Korea block (SK) is excluded from the Amurian plate (AM), coinciding with recent test results using fewer GPS sites [12]. Figure 5 shows residual velocities (observed minus predicted) at yearly observed and continuous GPS site in East Asia with respective to the 1 block (Eurasia), 2 blocks (Eurasia and East Asia) and 4 blocks (Eurasia, Amuria+S.Korea, North China and South China). The mean residual in 4-block model is much smaller than fewer blocks.

The estimated relative motions along the block boundaries are further obtained (Fig. 6). Comparisons of spreading or converging rates and directions along these boundaries are showing in Figures 7 and 8. The GPS-derived relative motion directions are nearly the same as the earthquake slip vector directions (Fig. 6). However there are some differences at Baikal Rift. It may be due to the larger uncertainty of earthquake slip vectors ( \pm 15 ). Another is possibly the Euler vector problem of the large non-rigid Eurasian plate (EU). For instance, Table 1 lists different Euler vectors of the Eurasian plate, and larger discrepancy is found 
between [5] and other geodetic results. The tectonic boundaries between the North China and Amuria plates, the Yin Shan-Yan Shan Mountain belts, are extending at about 2.4 $\mathrm{mm} / \mathrm{yr}$. The Qinling-Dabie fault between the North China and South China plates is moving left laterally at about $3.1 \mathrm{~mm} / \mathrm{yr}$. This difference between Amuria and South China predicted rates is about $5.5 \mathrm{~mm} / \mathrm{yr}$, almost consistent with geological results by [3] and [24]. The Tanlu fault between the North China and South Korea blocks is moving right laterally at about 3.8 $\mathrm{mm} / \mathrm{yr}$. The Amuria and South Korea blocks are extending at about $1.8 \mathrm{~mm} / \mathrm{yr}$. The convergent rates at the boundaries of the AM and Okhotsk [2] are from 9 to $17 \mathrm{~mm} / \mathrm{yr}$, similar to the seismic results of [17]. The spreading rates in the Baikal Rift zone are about $3.0 \pm 1.0$ $\mathrm{mm} / \mathrm{yr}$, consistent with [5] at $4 \pm 1 \mathrm{~mm} / \mathrm{yr}$.

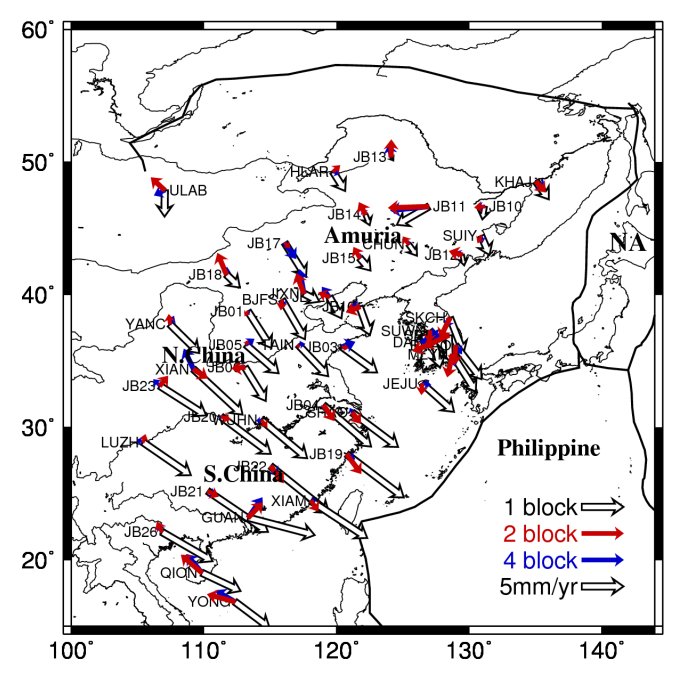

Figure 5. Residual velocities (observed minus predicted) at yearly observed and continuous GPS site in East Asia with respective to the 1 block (Eurasia), 2 blocks (Eurasia and East Asia) and 4 blocks (Eurasia, Amuria+S.Korea, North China and South China).

\begin{tabular}{lllllll}
\hline Plates & Longitude & Latitude & $\begin{array}{l}\text { Angular rate } \\
(\circ / \mathrm{My})\end{array}$ & $\begin{array}{l}\text { Pole } \\
\boldsymbol{\sigma}_{\text {maj }}\end{array}$ & $\begin{array}{l}\text { Error } \\
\boldsymbol{\sigma}_{\text {min }}\end{array}$ & $\begin{array}{l}\text { Ellipse } \\
\text { Azimuth }\end{array}$ \\
\hline This study & -100.655 & 56.995 & $0.257 \pm 0.002$ & 0.6 & 0.1 & 49 \\
\hline NNR-1A & -112.3 & 50.6 & 0.234 & & \\
\hline Altamimi et al.[2002] & -99.374 & 57.965 & $0.260 \pm 0.005$ & - & - \\
\hline Calais et al. [2003] & -107.022 & 52.266 & $0.245 \pm 0.005$ & - & - \\
\hline
\end{tabular}




\begin{tabular}{|c|c|c|c|c|c|c|}
\hline Longitude & & Latitude & $\begin{array}{l}\text { Angular rate } \\
(\circ / \mathrm{My})\end{array}$ & $\begin{array}{l}\text { Pole } \\
\sigma_{m a j}\end{array}$ & $\begin{array}{l}\text { Error } \\
\sigma_{\min }\end{array}$ & $\begin{array}{l}\text { Ellipse } \\
\text { Azimuth }\end{array}$ \\
\hline ITRF2000 b & -99.691 & 57.246 & $0.260 \pm 0.002$ & 0.8 & 0.2 & 52 \\
\hline Sella et al. [2002] & -102.21 & 58.27 & $0.257 \pm 0.003$ & 1.5 & 0.4 & 34 \\
\hline Kreemer et al.[2003] & -97.4 & 56.4 & $0.279 \pm 0.005$ & 0.6 & 0.2 & -81 \\
\hline \multicolumn{7}{|c|}{ Amurian Plate } \\
\hline This study & -115.285 & 62.474 & $0.291 \pm 0.004$ & 25.0 & 2.9 & 133 \\
\hline ITRF2000 b & -126.646 & 63.899 & $0.316 \pm 0.021$ & 10.9 & 0.9 & 146 \\
\hline Sella et al.[2002] & -133.76 & 63.75 & $0.327 \pm 0.057$ & 23.5 & 1.6 & -64 \\
\hline Kreemer et al. [2003] & -103.8 & 60.0 & $0.302 \pm 0.007$ & 1.3 & 0.5 & -20 \\
\hline \multicolumn{7}{|c|}{ South Korea } \\
\hline This study & 177.682 & 64.642 & $0.446 \pm 0.016$ & 42.3 & 1.5 & 19 \\
\hline \multicolumn{7}{|c|}{ North China } \\
\hline This study & -123.876 & 64.369 & $0.313 \pm 0.006$ & 40.0 & 2.8 & 137 \\
\hline \multicolumn{7}{|c|}{ South China } \\
\hline This study & -109.372 & 57.304 & $0.323 \pm 0.001$ & 20.2 & 2.0 & 127 \\
\hline Sella et al. [2002] & -109.21 & 54.58 & $0.340 \pm 0.057$ & 16.6 & 1.0 & -40 \\
\hline Shen et al. [2005] & 146.70 & 57.92 & 0.22 & - & - & - \\
\hline
\end{tabular}

Table 1. Rotation is in a clockwise direction about the pole. The error ellipses of the poles are described by the $1 \sigma$ semi-major and semi-minor axes of each error ellipse and the clockwise angle from true north of the semi-major axis. ${ }^{a}$ No-Net-Rotation NUVEL-1A (NNR-1A) model [6] ${ }^{b}$ Angular velocity vectors were estimated from 12 years of CGPS in ITRF2000 [25]Absolute and relative angular velocity vectors for the Eurasian, Amurian, South Korea, North China and South China plates.

\begin{tabular}{ccccc}
\hline Number of blocks $^{\text {a }}$ & $\boldsymbol{x}^{\mathbf{2}}$ & $\boldsymbol{x}_{\boldsymbol{f}}^{\mathbf{2}}$ & $\boldsymbol{f}$ & $\mathbf{F}$ \\
\hline 1 & 5904.8 & 6.4 & 922 & \\
\hline 2 & 1295.4 & 1.4 & 939 & 1086.5 \\
\hline 3 & 1221.2 & 1.3 & 936 & 18.5 \\
\hline 4 & 1191.5 & 1.3 & 933 & 7.6 \\
\hline 5 & 980.5 & 1.1 & 930 & 65.0 \\
\hline
\end{tabular}

Table 2. ${ }^{a}$ 1: EU (Eurasia); 2: EU and EA (East Asia); 3: EU, AN (Amuria+South Korea+North China) and SC (South China); 4: EU, AK (Amuria+S.Korea), NC, SC; 5: EU, NC, SC, AM and SK; 6: EU, NC, SC, SK, West AM and East AM. $f$ is the number of degrees of freedom and $x_{f}^{2}$ is the reduced $x^{2}$ as the ratio of $x^{2}$ to $f$. Statistic tests of different block models 


\section{Crustal Strain rates and Seismic Risks}

Monitoring the pattern of crustal strain and comprehensive understanding of strain accumulation intensity are beneficial to reveal the physical process of crustal tectonic activities and to evaluate the earthquake risk. As the first step in the earthquake risk potential evaluation in East Asia, the strain parameters are estimated from the estimated GPS displacement rate field. In order to reduce the effects of abnormal site motions, the subnetwork with four GPS sites is used to estimate the strain parameters. Under the hypothesis that the velocity field $v$ varies linearly inside each small sub-network covering the GPS sites, we can calculate the average horizontal velocity gradient $g=\operatorname{grad}(v)$ over each subnetwork. Because the velocity gradient generally incorporates both deformation and rotation, this 2-D tensor is asymmetric [21]. The crustal strain rate in East Asia can be derived from GPS deformation velocities by $[12,14]$ :

$$
\begin{aligned}
& v_{e i}=\frac{\partial v_{e i}}{\partial x_{e i}} x_{e i}+\frac{\partial v_{e i}}{\partial x_{n i}} x_{n i} \\
& v_{n i}=\frac{\partial v_{n i}}{\partial x_{e i}} x_{e i}+\frac{\partial v_{n i}}{\partial x_{n i}} x_{n i}
\end{aligned}
$$

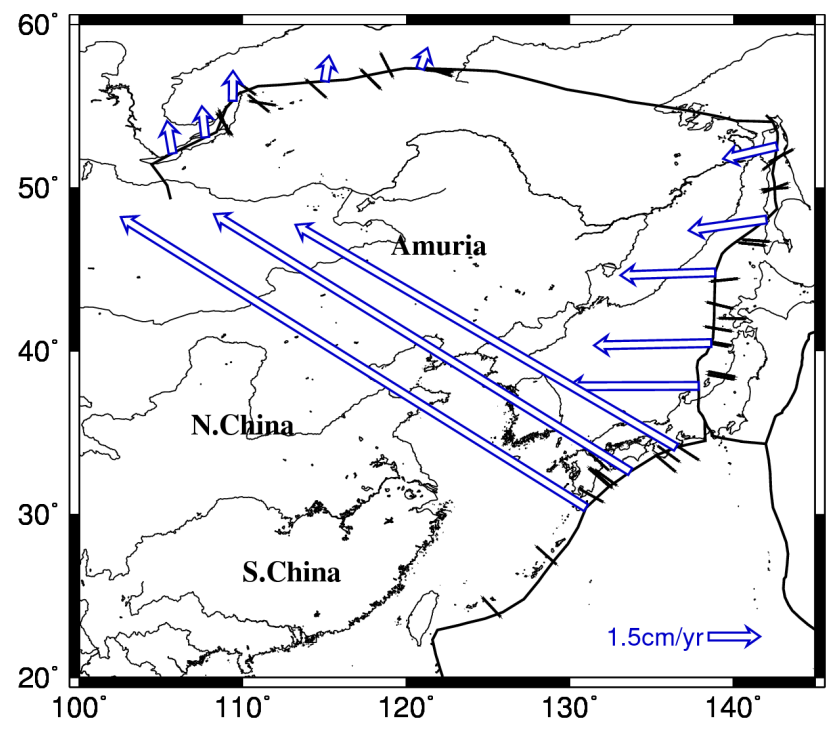

Figure 6. Relative spreading or converging motions at the plate boundaries in East Asia. 


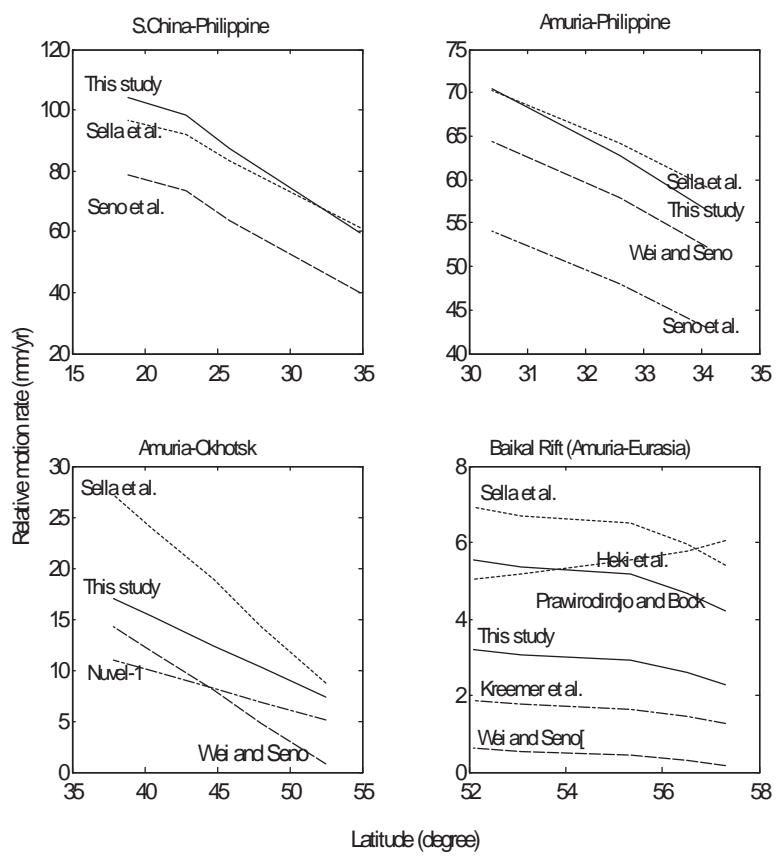

Figure 7. Relative spreading or converging rates at the plate boundaries in East Asia.

where $v_{e i}$ and $v_{n i}$ are the east and north component velocity at the site $i$ located at $\left(x_{e i}, x_{n i}\right)$.

Strain components $\dot{\varepsilon}_{e e}, \dot{\varepsilon}_{n n}$ and $\dot{\varepsilon}_{\text {en }}$ are expressed as $\frac{\mathrm{\partial} v_{e}}{\mathrm{\partial} x_{e}}, \frac{\mathrm{\partial} v_{n}}{\mathrm{\partial} x_{n}}$ and $\frac{1}{2}\left(\frac{\mathrm{\partial} v_{e}}{\mathrm{\partial} x_{n}}+\frac{\mathrm{\partial} v_{n}}{\mathrm{\partial} x_{e}}\right)$, respectively. The dilation rates i show that East Asia is under the compressional strain regime at WNW-ENE, consistent with the focal mechanism of earthquakes in Northeast Asia. The high dilation rates appear in North China, Southwest Japan and at the boundary of Philippine Sea plate. The strong compression rates are probably caused by the extrusion force due to the subduction of the Philippine Sea and Pacific plates and the expulsion of Eurasian plate with Indian plate collision, causing frequent earthquakes in these regions. Inversely, the South Korea and South China blocks have relatively lower dilation rates, indicating a lower indirect effect of push and subduction forces or as if such forces are transmitted through South Korean peninsula and South China without causing any deformation/strain, alternatively. This may be attributed to the strong rheology or/and absence of relatively weak zones in the region.

In addition, we estimate the scalar strain rate, defined as

$$
\dot{\varepsilon}=\sqrt{\dot{\varepsilon}_{e e}^{2}+\dot{\varepsilon}_{n n}^{2}+2 \dot{\varepsilon}_{e n}^{2}}
$$


where $e$ and $n$ are longitude and latitude directions, respectively. Figure 9 shows the contour map of scalar strain rates in Northeast Asia, implying the Korean peninsula and South China as stable blocks with low strain rates. It once again highlights that high strain rates concentrate in North China, Southwest Japan and the boundary of Philippine Sea plate with Eurasian plate, consistent with high seismicity in these areas (Figure 1).

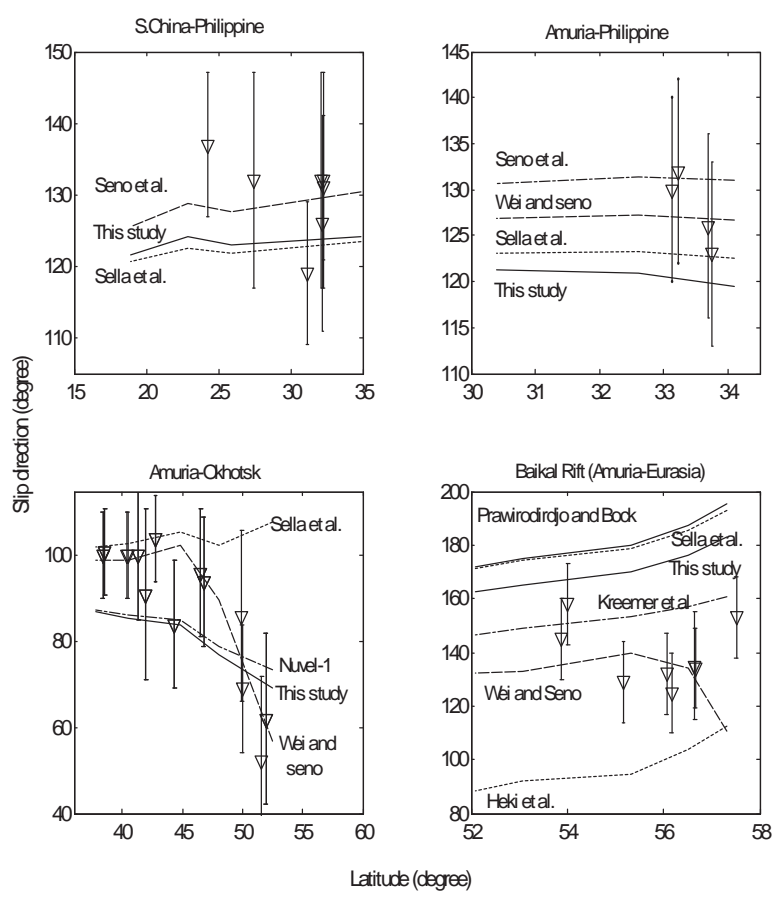

Figure 8. Relative spreading or converging directions at the plate boundaries in East Asia.

In addition, the accumulated strain energy is generally released through earthquakes until the adjacent fault blocks or plates reach a new state of equilibrium [26, 33]. Therefore, the release of tectonic strain energy stored within crustal rock is the cause of major earthquakes. The strain energy per unit volume (i.e. the strain energy density) is an important index reflecting the intensity of crustal activities, and its variation rate indicates the long-term trend of accumulated energy within the crust. The larger the variation rate of strain energy density, the higher energy accumulated in the crust, which would more probably result in earthquakes. Therefore, for the earthquake risk evaluation and prediction, it is important to estimate the strain energy density from surface displacement observations and determine the state of strain energy density within the crust and its temporal variations. 


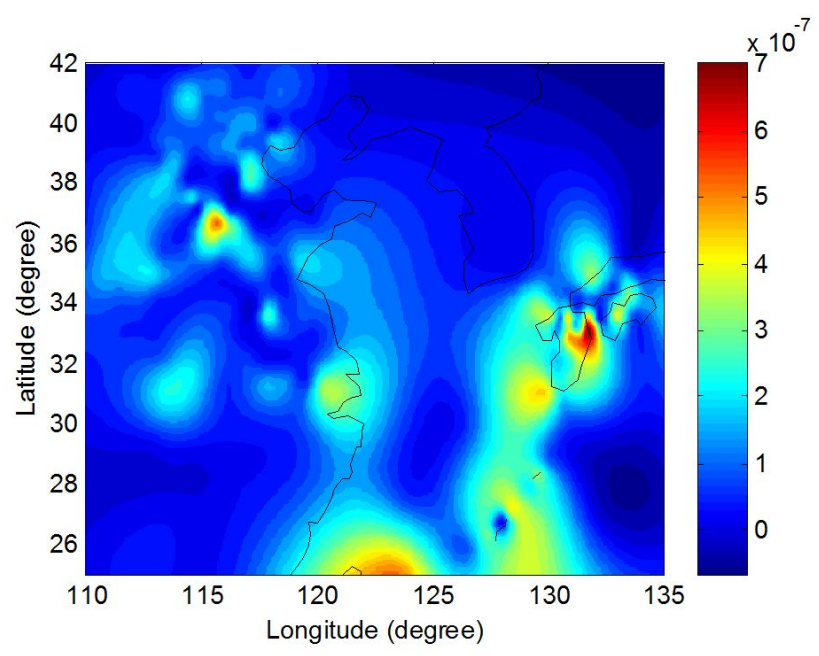

Figure 9. Map of scalar strain rates in East Asia from GPS observations.

For an elastic body, the strain energy equals the work done by external forces and its density is the strain energy per unit volume. The general tensor form for the strain energy density can be expressed in terms of strain and stress using Hooker's Law:

$$
U=\frac{1}{2} \sigma_{i j} \varepsilon_{i j}
$$

where $U$ is the strain energy density (Unit: $J . m^{-3}$ ), $\sigma_{i j}$ and $\varepsilon_{i j}$ are the stress and strain, respectively. And the variation rate of strain energy density can be further derived from Eq. (6). The stress is obtained through the laws of elasticity theory as follows [31]:

$$
\sigma_{i j}=2 \mu \varepsilon_{i j}+\delta_{i j} \lambda \Delta
$$

where $\mu$ is the modulus of rigidity, $\lambda$ is the Lame parameter, $\delta_{i j}$ is Kroneckerdelta, $\Delta$ is the 2D surface dilation $\left(\sum_{i=1}^{2} \varepsilon_{i i}\right)$. For Poisson's ratio $v=0.25, \lambda=\mu$, and it is assumed as standard value of $3 \times 10^{10} \mathrm{~Pa}[7]$.

The stress $\left(\sigma_{i j}\right)$, strain $\left(\varepsilon_{i j}\right)$ and their rates can be derived from GPS displacements (1999-2004) and velocities, respectively. Using Eq. (6), the strain energy density variation rate in East Asia can be obtained using the derived the strain, stress and their rates, which is shown in Figure 10. The distribution of strain energy density variation rates shows that the 
most active areas are in North China, Southwest Japan and west margin of Philippine Sea plate, respectively, again consistent with high seismic activity zones. As the GPS measurements are made after the large historic earthquakes, the strain energy density rates derived from GPS displacement rate may include contributions from postseismic relaxation. These regions with anomalous large strain energy density rates probably indicate a high earthquake risk in future, and the lower strain energy density rates in the South Korean peninsula and South China imply that low seismicity may continue in the future.

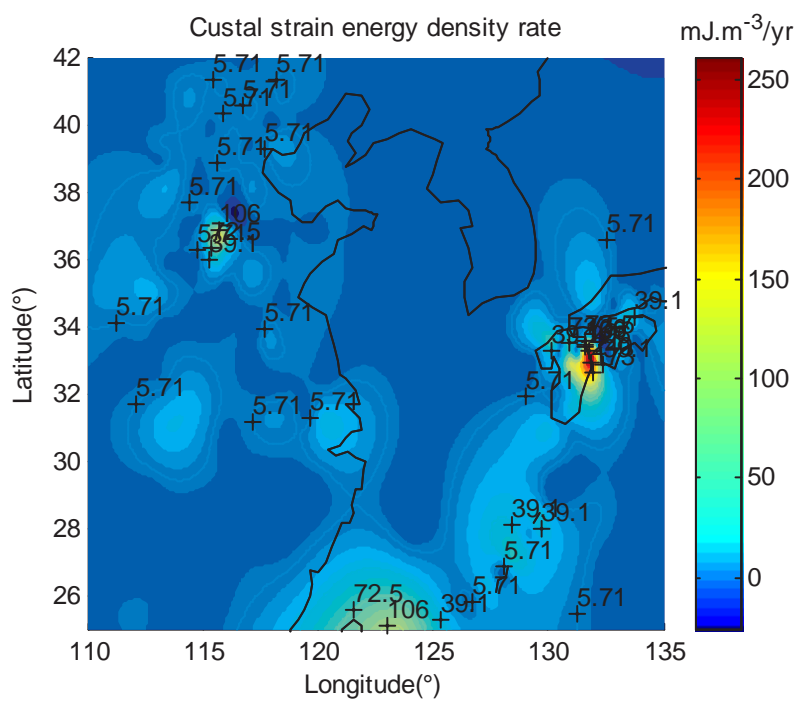

Figure 10. Variation rate of crustal strain energy density in East Asia

\section{Conclusions}

GPS data (1998-2005) from more than 85 continuous and about 1000 campaign stations in East Asia have been processed. The kinematics of East Asia is studied by modeling GPS-derived velocities with rigid block rotations and elastic deformation. It has been found that the deformation in East Asia can be well described by a number of rotating blocks, which are independent of the Eurasian plate motion with statistical significance above the $99 \%$ confidence level. The tectonic boundary between the North China and Amuria plates is the Yin Shan-Yan Shan Mountain belts with about $2.4 \mathrm{~mm} / \mathrm{yr}$ extension. The boundary between North China and South China is the Qinling-Dabie fault, moving left laterally at about 3.1 $\mathrm{mm} / \mathrm{yr}$. The Amuria and South Korea blocks are extending at about $1.8 \mathrm{~mm} / \mathrm{yr}$. The Baikal Rift between the Amurian and Eurasian plates is spreading at about $3.0 \mathrm{~mm} / \mathrm{yr}$. The 9 17 $\mathrm{mm} / \mathrm{yr}$ relative motion between the Amuria and Okhotsk blocks is accommodated at the East Sea-Japan trench zone. Furthermore, the relative motion rates and deformation types 
are nearly consistent with seismic and geological solutions along their boundaries. In addition, the AM, SK and SC blocks are almost rigid with residual velocities on order of 1.0 1.2 $\mathrm{mm} / \mathrm{yr}$, while the NC block has larger residual velocities on order of $1.6 \mathrm{~mm} / \mathrm{yr}$, indicating un-modeled deformation in block boundaries. Localized deformation near the Qinling-Dabie fault and Yin Shan-Yan Shan Mountain belts may be elastic strain accumulation due to interseismic locking of faults.

The strain and energy density rates in East Asia are investigated with GPS observations (1999.1-2004.12). The dilation rates show that East Asia is under the compressional strain regime at WNW-ENE, consistent with the focal mechanism of earthquakes in East Asia. The high dilation rates focus on North China, Southwest Japan and the boundary of Philippine Sea plate, probably caused by the compression force due to the subduction of the Philippine Sea and Pacific plates and the expulsion of Eurasian plate with Indian plate collision. In contrast, the South Korean Peninsula and South China blocks havbe relatively lower dilation rates, indicating a possible lower effect of push and subduction forces or that such forces are transmitted through South Korean peninsula and South China without causing any deformation/strain. This may be attribute to the strong rheology or/and absence of weak zones in the region, which leads to fewer earthquakes. Moreover, the scalar strain rates and strain energy density rates further imply the Korean peninsula and South China as a stable block with low rates, and high rates mainly concentrate on North China and Southwest Japan and the western boundary of Philippine Sea plate, consistent with highly seismic occurrences in these areas. In addition, the strain energy density rate reflects a long-term trend of strain energy accumulation and release. Therefore, North China, Southwest Japan and western boundary of Philippine Sea plate with high strain energy density rates are still highly seismic and the low seismicity in South Korea and South China with lower strain energy density rates may continue in the future.

\section{Acknowledgements}

Figures were made with the public domain software GMT [Wessel and Smith, 1998]. We are grateful to those who created the Crustal Motion Observation Network of China and made the observation data available, Korean GPS Network and Japan GPS Earth Observation Network (GEONET).

\section{Author details}

Shuanggen Jin

Shanghai Astronomical Observatory, Chinese Academy of Sciences, Shanghai, China 


\section{References}

[1] Altamimi, Z., Sillard, P., \& Boucher, C. (2002). ITRF2000: A New Release of the International Terrestrial Reference Frame for Earth Science Applications. J. Geophys. Res, 107(A10), 2214, 10.1029/2001JB000561.

[2] Apel, E. V., Burgmann, R., Steblov, G., Vasilenko, N., King, R., \& Prytkov, A. (2006). Independent active microplate tectonics of northeast Asia from GPS velocities and block modeling. Geophys. Res, 33, L11303, 10.1029/2006GL026077.

[3] Avouac, J. P., \& Tapponnier, P. (1993). Kinematic model of deformation in central Asia, . Geophys. Res. Lett, 20, 895-898.

[4] Bird, P. (2003). An updated digital model of plate boundaries. Geochem. Geophys. Geosyst, 4(3), 1027, 10.1029/2001GC000252.

[5] Calais, E., Vergnolle, M., San'kov, V., Lukhnev, A., Miroshnitchenko, A., Amarjargal, S., \& Déverchère, J. (2003). GPS measurements of crustal deformation in the BaikalMongolia area (1994-2002): Implications for current kinematics of Asia. J. Geophys. Res, 108(B10), 2501, 10.1029/2002JB002373.

[6] De Mets, C., Argus, D. F., Gordon, R. G, et al. (1990). Current plate motions. Geophys J Int, 101, 425-478.

[7] Hanks, T. C., \& Kanamori, H. (1979). A moment-magnitude scale. J. Geophys. Res., 84, 2348-2350.

[8] Heki, K., Miyazaki, S., Takahashi, H., Kasahara, M., Kimata, F., Miura, S., \& An, K. (1999). The Amurian plate motion and current plate kinematics in East Asia. J. Geophys. Res, 104, 29147-29155.

[9] Herring, A. (2002). GLOBK global Kalman filter VLBI and GPS analysis program, version 10.0, Mass. Inst. of Technol., Cambridge Mass, USA.

[10] Jin, S. G., \& Zhu, W. (2002). Present-day spreading motion of the mid-Atlantic ridge. Chin. Sci. Bull, 47(18), 1551-1555, 10.1360/02tb9342.

[11] Jin, S. G., \& Zhu, W. Y. (2003). Active Motion of Tectonic Blocks in Eastern Asia: Evidence from GPS Measurements. ACTA Geological Sinica-English Edition, 77(1), 59-63.

[12] Jin, S. G., \& Park, P. (2006). Crustal stress and strain energy density rates in South Korea deduced from GPS observations. Terr. Atmos. Ocean. Sci, 17(1), 169-178.

[13] Jin, S. G., Park, P., \& Zhu, W. (2007). Micro-plate tectonics and kinematics in Northeast Asia inferred from a dense set of GPS observations. Earth Planet. Sci. Lett, 257(3-4), 486-496, 10.1016/j.epsl.2007.03.011, 2007a.

[14] Jin, S. G., Park, P., \& Park, J. (2007 b). Why is the South Korean peninsula largely aseismic? Geodetic evidences. Curr. Science, 93(2), 250-253. 
[15] Kato, T., Kaotake, Y., \& Nakao, S. (1998). Initial results from WING, the continuous GPS network in the western Pacific area. Geophysical Research Letters, 125(3), 369-372.

[16] King, R. W., \& Bock, Y. (1999). Documentation for the GAMIT GPS Analysis Software. Mass. Inst. of Technol., Cambridge Mass.

[17] Kogan, M. G., Bürgmann, R., Vasilenko, N. F., Scholz, C. H., King, R. W., Ivashchenko, A. I., Frolov, D. I., Steblov, G. M., Kim, Ch U., \& Egorov, S. G. (2003). The 2000 M w 6.8 Uglegorsk earthquake and regional plate boundary deformation of Sakhalin from geodetic data. Geophys. Res. Lett, 30(3), 1102, 10.1029/2002GL016399.

[18] Kogan, M. G., Steblov, G. M., King, R. W., Herring, T. A., Frolov, D. L., Egorov, S. G., Levin, V. Y., \& Jones, A. (2000). Geodetic constrains on the rigidity and relative motion of Eurasian and North American. Geophys. Res. Lett, 27, 2041-2044.

[19] Kreemer, C., Holt, W. E., \& Haines, A. (2003). An integrated global model of presentday plate motions and plate boundary deformation. Geophys. J. Int, 8-34.

[20] Meade, B. J., \& Hager, B. H. (2005). Block models of crustal motion in southern California constrained by GPS measurements. J. Geophys. Res, 110, B03403, 10.1029/2004JB003209.

[21] Malvern, L. E. (1969). Introduction to the mechanics of a continuum medium. Prentice-Hall, Englewood Cliffs, NJ.

[22] Molnar, P., \& Tapponnier, P. (1975). Cenozoic tectonic of Asia: effects of a continental collision. Science, 189, 419-426.

[23] Okada, Y. (1985). Surface deformation due to shear and tensile faults in a half space. Bull. Seismol. Soc. Am, 75, 1135-1154.

[24] Peltzer, G., \& Saucier, F. (1996). Present-day kinematics of Asia derived from geologic fault rates. J. Geophys. Res, 101(27).

[25] Prawirodirdjo, L., \& Bock, Y. (2004). Instantaneous global platemotionmodel from 12 years of continuous GPS observations. J. Geophys. Res, 109, B08405, 10.1029/2003JB002944.

[26] Savage, J. C., \& Simpson, R. W. (1997). Surface strain accumulation and the seismic moment tensor. Bulletin Seismic Society of America, 87, 1345-1353.

[27] Sella, G. F., Dixon, T. H., \& Mao, A. (2002). REVEL: A model for recent plate velocities from space geodesy. J Geophys Res, 107(B4), ETG11-1-32.

[28] Shen, Z., , K., Lü, J., Wang, M., \& Bürgmann, R. (2005). Contemporary crustal deformation around the southeast borderland of the Tibetan Plateau. J. Geophys. Res, 110, B11409, 10.1029/2004JB003421.

[29] Steblov, G. M., Kogan, M. G., King, R. W., Scholz, C. H., Bürgmann, R., \& Frolov, D. I. (2003). Imprint of the North American plate in Siberia revealed by GPS. Geophys. Res. Lett, 30(18), 1924, 10.1029/2003GL017805. 
[30] Stein, S., \& Gordon, R. (1984). Statistical tests of additional plate boundaries from plate motion inversions. Earth Planet. Sci. lett, 69, 401-412.

[31] Straub, C. (1996). Recent crustal defoirmation and strain accumulation in the Marmara sea region, inferred from GPS measurements. Ist. of Geod. and Photogram. FTHZ Mitt., 58.

[32] Thatcher, W. (2007). Microplate model for the present-day deformation of Tibet. J. Geophys. Res, 112, B01401, 10.1029/2005JB004244.

[33] Weber, J., Stein, S., \& Engeln, J. (1998). Estimation of intraplate strain accumulation in the New Madrid seismic zone from repeat GPS surveys. Tectonics, 17, 250-266.

[34] Wei, D., \& Seno, T. (1998). Determination of the Amurian plate motion, in Mantle dynamics and plate interaction in East Asia. edited by M. Flower, S. Chung, C. Lo and T. Lee, 337-346.

[35] Wessel, P., \& Smith, W. H. F. (1998). New, improved version of Generic Mapping Tools released: Eos. Trans. Amer. Geophys. Union, 79, 579.

[36] Zonenshain, L. P., \& Savostin, L. A. (1981). Geodynamics of the Baikal rift zone and plate tectonics of Asia. Tectonophysics, 76, 1-45. 